\title{
p-Type a-Si:H Doping Using Plasma Immersion Ion Implantation for Silicon Heterojunction Solar Cell Application
}

\author{
Tristan Carrere,* Delfina Muñoz, Marianne Coig, Christophe Longeaud, \\ and Jean-Paul Kleider
}

Plasma immersion ion implantation doping of thin a-Si:H layers is proposed as a new and easy-to-process solution for the fabrication of interdigitated back contacted a-Si/c-Si heterojunction solar cells (SHJ). This study is focused on boron implantation (at low acceleration voltages in the range of 500-1500 V) in a-Si:H layers on a c-Si substrate, to create the strongly doped emitter while maintaining very high c-Si surface passivation, required for high efficiency $\mathrm{SHJ}$ solar cells. The influence of implantation parameters and postannealing temperature on the a-Si: $\mathrm{H}$ layer conductivity and passivation quality are assessed. The doped layers conductivity is also investigated by direct and indirect electrical characterization of the density of states in a-Si:H after ion implantation, and the post-implantation annealing. Eventually, an interesting passivation/doping trade-off is obtained after annealing at $300{ }^{\circ} \mathrm{C}$ of samples implanted at $1000 \mathrm{~V}$ with implied open circuit voltage values of $710( \pm 5) \mathrm{mV}$ and conductivity values of the doped a-Si:H layer of $3.0( \pm 1.0) \times 10^{-5} \Omega^{-1} \mathrm{~cm}^{-1}$, which demonstrates that such approach is promising for processing IBC-SHJ cells. metallic contacts, thus strongly improving the cells current. ${ }^{[2]}$ Consequently, the IBC$\mathrm{SHJ}$ has recently reached the record efficiency of single-junction silicon solar cells with $25.6 \% .^{[3]}$

However, the patterning of both the hydrogenated amorphous silicon (a-Si:H) and the TCO layers is known to be complex. For instance, processes using sacrificial layers and laser, ${ }^{[4]}$ hard masks and plasma etching, ${ }^{[5]}$ and photolithography ${ }^{[6]}$, have been reported.

Therefore, ion implantation is proposed as a promising solution for amorphous silicon doping. Indeed, three decades ago, the ability of ion implantation to efficiently dope (n)- and (p)-a-Si:H layers has been demonstrated. ${ }^{[7-9]}$ Thus, ion implantation is a promising candidate to decrease manufacturing costs thanks to an easy-toprocess solution for localized impurity production with the simple addition of hard masks.

Introduction: The interdigitated back contact amorphous/ crystalline silicon (a-Si:H/c-Si) heterojunction solar cell (IBC$\mathrm{SHJ}$ ) is one of the most promising architectures. Indeed, the standard $\mathrm{SHJ}$ cell architecture already achieved very high efficiencies $\left(25.1 \%\right.$ on large area $\left.{ }^{[1]}\right)$, and the interdigitated back contact architecture allows to suppress shadowing related to the

T. Carrere, D. Muñoz

CEA-INES, LITEN, Laboratoire HET, 50 Avenue du Lac

Léman, F-73375 Le Bourget-du-Lac, France

E-mail: delfina.munoz@cea.fr

T. Carrere, C. Longeaud, J.-P. Kleider

GeePs, UMR8507 CNRS, CentraleSupélec, Université

Paris-Sud, Université Paris-Saclay, Sorbonne Uni-

versités UPMC Univ Paris 6, 11 rue Joliot Curie,

F-91192 Gif-sur-Yvette Cedex, France

T. Carrere

French Environment and Energy Management Agency,

20 Avenue du Grésillé BP 90406, F-49004 Angers

Cedex 01, France

M. Coig

CEA-LETI, MINATEC Campus, 17 rue des Martyrs,

F-38054 Grenoble, France

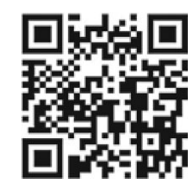

DOI: 10.1002/solr.201600007
However, the challenge of ion implantation implementation for $\mathrm{SHJ}$ cells processing is to maintain a high passivation quality at the critical hetero-interface, despite the very thin a-Si:H layers. A recent study has evidenced strong interface degradations upon beam-line ion implantation (BLII) in thick a-Si:H layers $(45 \mathrm{~nm}) \cdot{ }^{[10]}$ Although optimization of BLII conditions is probably still possible, in this paper, we propose to use a plasma immersion ion implantation (PIII) process where the sample is directly immersed in the precursor gas. ${ }^{[11,12]}$ This configuration allows working at low acceleration energies and is able to shallowly implant the species. Therefore, it appears as a new solution to decrease a-Si:H/c-Si interface damages so that a trade-off between a-Si:H doping and interface passivation quality should be possible.

Using PIII, the goal of this study is to investigate the p-type doping of thin a-Si:H layers $(25 \mathrm{~nm})$ for the SHJ cell application, i.e., combining both an efficient (p) a-Si:H doping and a high c-Si substrate passivation.

Materials and methods: $25 \mathrm{~nm}$ thick (i) a-Si:H layers are deposited by RF-PECVD on $1 \mathrm{~mm}$ thick corning glass and on $<100>$ FZ-grown $180 \pm 20 \mu \mathrm{m}$ thick, $3.0 \pm 0.1 \Omega \mathrm{cm}$ mirror-like polished 4 inch (n) c-Si substrates. Glass samples are dedicated to a-Si:H layers conductivity measurements, and double side 
passivated c-Si substrates to lifetime and spectroscopic ellipsometry (SE) measurements.

After deposition, (i) a-Si:H layers are implanted at CEA-Leti using a PULSION ${ }^{\mathrm{B}}$ PIII tool. $\mathrm{B}_{2} \mathrm{H}_{6}$ is used as a precursor gas. Low implantation energies of 500,1000, and $1500 \mathrm{~V}$ and doses of $10^{15}, 5 \times 10^{15}$, and $10^{16} \mathrm{~cm}^{-2}$ have been tested. The pressure was set to $3.4 \times 10^{-3} \mathrm{mbar}$, the substrate was maintained at room temperature during implantation, and the implantation time $10^{16} \mathrm{~cm}^{-2}$. It is very unlikely that ions lose energy due to collisions in the sheath, and therefore the ion implantation energy is completely determined by the acceleration voltage over the sheath. Let us note that the dose control system is similar to that of BLII implanters. However, because there is no mass selection, there are many different ionized species implanted and thus the measured charges amount entering the layer does not correspond precisely to the boron (B) dose. Therefore, the real boron dose might be slightly different from the nominal dose. This effect is particularly true for low implantation energies $(<1500 \mathrm{~V}) .^{[13]}$

Then samples are annealed for $30 \mathrm{~min}$ on a hot plate with temperatures ranging from 150 to $300^{\circ} \mathrm{C}$. SE, carrier lifetime and conductivity measurements, are performed after each step ((i) a-Si:H deposition, PIII, cumulative annealing steps). SE measurements are performed using a Jobin-Yvon UVISEL setup and the obtained data are fitted following Tauc Lorenz and using Jellison's approximation. ${ }^{[14]}$ The carrier lifetime is measured using a WCT-120 Sinton Instrument setup ${ }^{[15]}$, while the a-Si:H conductivity is deduced from current-voltage $(I-V)$ measurements on samples on glass where top co-planar Al electrodes were evaporated.

To have a deeper insight into the material and electrical properties, some samples have been submitted to secondary ion mass spectroscopy (SIMS), temperature-dependent photoconillumination with a dc photon flux of $10^{14} \mathrm{~cm}^{-2} \mathrm{~s}^{-1}$.

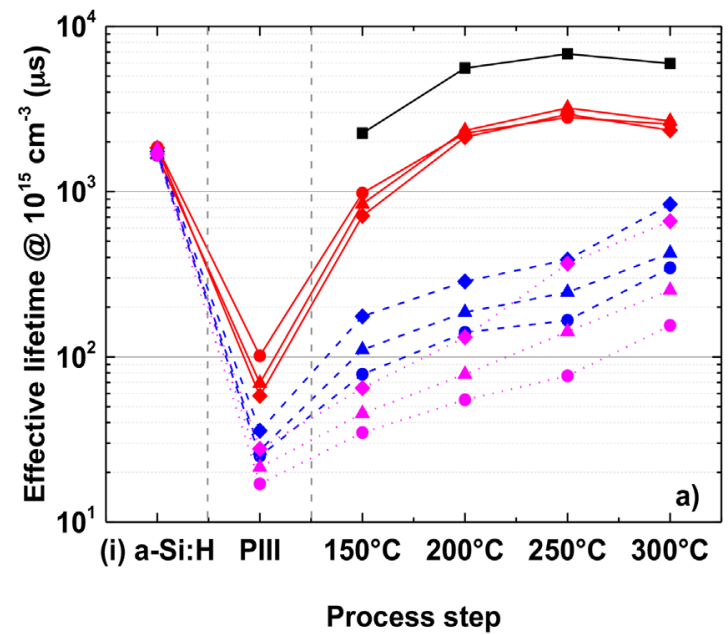
was varied to vary the dose, with a maximum of $300 \mathrm{~s}$ for ductivity and modulated photocurrent (MPC) ${ }^{[16]}$ using a $450 \mathrm{~nm}$

Results and discussions. Lifetime measurements: As illustrated in Figure 1, lifetimes close to $2 \mathrm{~ms}$ are obtained (at an injection level of $10^{15} \mathrm{~cm}^{-3}$ ) after (i) a-Si:H deposition. After PIII, whatever the implantation conditions, the effective lifetime drops to values lower than $100 \mu$ s (Figure 1a). Illiberi et al. ${ }^{[17]}$ conducted $\mathrm{Ar}^{+}$ implantation experiments at low implantation energy using standard beam-line ion implantation, where the effect of energy was very weak, while the dose had a strong impact. ${ }^{[17]}$ In our case, the decrease is mainly controlled by the implantation energy. The fact that the implantation dose has only a second order influence here (seen for $500 \mathrm{~V}$ implantation only) and that $\mathrm{B}$ atoms are found at the a-Si:H/c-Si interface in all conditions suggests that the effective lifetime decrease originates from direct implantation damages.

Meanwhile, after annealing, the effective lifetime strongly increases with annealing temperature. The effective lifetime dependence on annealing time has been found logarithmic implying little further recovery after $30 \mathrm{~min}$ of annealing, independently of the process conditions. Therefore, a $30 \mathrm{~min}$ annealing is performed at each temperature step. For temperatures up to $200^{\circ} \mathrm{C}$, the lifetime recovery rate is lower for samples implanted at higher energies. At temperatures $>250^{\circ} \mathrm{C}$, for 1000 and $1500 \mathrm{~V}$ implanted samples, passivation recovery after annealing is also improved with increasing the doses. Since a higher dose or a higher implantation energy leads to a higher boron concentration at the a-Si:H/c-Si interface, the results can be explained by an improvement of field-effect passivation provided by the doped a-Si:H region. The fact that this behavior appears at high temperature suggests that an effective doping (i.e., dopant activation) is only obtained at such temperatures. Only samples implanted at the lowest energy succeed to reach an effective lifetime value similar to our (i) a-Si:H/(n) c-Si/(i) a-Si:H reference. It is worth emphasizing that at $300^{\circ} \mathrm{C}$, these samples and the reference exhibit a slight lifetime decrease probably due to hydrogen effusion (the deposition temperature is $200^{\circ} \mathrm{C}$ for all layers) ${ }^{[18]}$ All samples have been measured again a few months



Figure 1. Measured (a) effective lifetime at low injection level $\left(10^{15} \mathrm{~cm}^{-3}\right)$ and $(\mathrm{b})$ 1-sun implied $V_{O C}\left(\mathrm{i}-V_{\mathrm{OC}}\right)$ for samples implanted at different energies (red full lines: $500 \mathrm{~V}$, blue-dashed lines: $1000 \mathrm{~V}$, pink-dotted lines: $1500 \mathrm{~V}$ ), and doses $\left(\mathbf{0}: 10^{15} \mathrm{~cm}^{-2}, \boldsymbol{\Delta}: 5 \times 10^{15} \mathrm{~cm}^{-2}, \bullet: 10^{16} \mathrm{~cm}^{-2}\right)$, and reference sample (black squares) after each process step (a-Si:H deposition, PIII implantation, and cumulative 30 min annealing steps with increasing temperatures). 
after implantation and annealing with the reproducible results confirming that such lifetime recovery is a stable mechanism.

Figure $1 \mathrm{~b}$ shows that an implied- $V_{\mathrm{OC}}\left(\mathrm{i}-V_{\mathrm{OC}}\right)$ value of $700 \mathrm{mV}$ is reached for low energy $(500 \mathrm{~V})$ implanted samples only. For higher energies, a higher temperature might be able to further improve the passivation recovery up to $700 \mathrm{mV}$. However, other phenomena such as layers oxidation, stronger $\mathrm{H}$ effusion or a-Si:H crystallization could appear above $300^{\circ} \mathrm{C}$ and mitigate the beneficial annealing effects.

Conductivity at room temperature: While PECVD deposition results in a homogeneous boron dopant concentration throughout the layer thickness using an ion implantation process leads to non-homogeneous boron profiles. However, SIMS measurements revealed that these non-homogeneous profiles exhibited only small dependence on ion energy, with a characteristic decrease length of about $6 \mathrm{~nm}$. We thus used this value to translate the measured conductance of the samples into an effective conductivity in order to compare the influence of implantation parameters and thermal annealing steps on the transport properties (see Figure 2).

As expected, after PIII implantation, the dark room temperature (RT) conductivity is very low $\left(<10^{-6} \Omega^{-1} \mathrm{~cm}^{-1}\right)$. For implantation conditions at 1000 and $1500 \mathrm{~V}$ increasing the dose seems to decrease the a-Si:H layer conductivity.

A low temperature $\left(150^{\circ} \mathrm{C}\right)$, annealing tends to decrease the dispersion and gather the samples conductivity between $10^{-9}$ and $10^{-7} \Omega^{-1} \mathrm{~cm}^{-1}$ thus decreasing the conductivity of some samples. A conductivity decrease was already observed after annealing following ion implantation inducing a high amount of damages. ${ }^{[19]}$ Such behavior was linked to a decrease in the density of localized states (DOS) that promote current transport through hopping mechanisms. For our samples, such assertion is supported by the fact that the samples which conductivity is decreased after the $150^{\circ} \mathrm{C}$ annealing have been implanted at the higher energies. Therefore, these are the samples with the higher damage content and thus, the higher DOS.

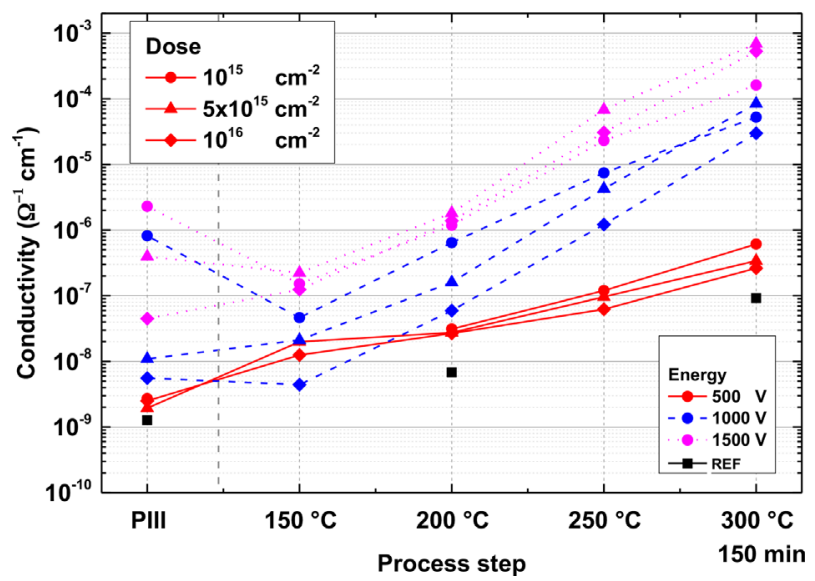

Figure 2. Measured effective room temperature conductivity of (p) a-Si:H layers implanted at different energies and doses (see Figure 1), after each process step: just after implantation (PIII) and after subsequent annealing steps at increasing temperatures $(150,200,250$, and prolonged annealing at $300^{\circ} \mathrm{C}$ ). For the reference sample, the conductivity before annealing is reported at the PIII step.
Annealing at temperatures above $150^{\circ} \mathrm{C}$ increases the conductivities of all samples. As for passivation recovery, the conductivity increase upon annealing is also temperature activated. However, only the samples implanted at 1000 and $1500 \mathrm{~V}$ have conductivities surpassing the (i) a-Si:H reference. This indicates either a very low dose of $500 \mathrm{~V}$-implanted dopants (at low acceleration voltage some of the ions may not penetrate into the sample and stay at the surface) or a very small doping efficiency, due to the strong concentration of dopant atoms near the surface (since lower implantation energy leads to thinner depth profile).

The maximum in conductivity is obtained for $1500 \mathrm{~V}$ implanted samples and seems to be dose independent. Since the boron depth profiles are very similar after implantation at 1000 and $1500 \mathrm{~V}$, there cannot be a concentration-dependent doping efficiency but it seems that the boron activation upon annealing depends on the implantation energy. As a result, samples implanted at $1500 \mathrm{~V}$ and at doses of $5 \times 10^{15}$ and $10^{16} \mathrm{~cm}^{-2}$ succeed to reach conductivities above $10^{-4} \Omega^{-1} \mathrm{~cm}^{-1}$ (currently used for SHJ cells ${ }^{[18]}$ ), compared to $10^{-2} \Omega^{-1} \mathrm{~cm}^{-1}$ already achieved using BLII implantation and with a similar average boron concentration $\left([\mathrm{B}] \sim 10^{22} \mathrm{~cm}^{-3}\right) .{ }^{[20]}$

To explain this difference, one can first note that implanted dopant activation is lower than in PECVD-doped layers. ${ }^{\text {[20] }}$ Moreover, the activation difference with Le Comber's experiment might originate from the PIII parasitic implantation of $\mathrm{C}$ and $\mathrm{F}$ atoms that is revealed from SIMS measurements. They are known to decrease the a-Si:H layer conductivity and act as n-type doping, respectively. ${ }^{[9,21]}$ Finally, the implantation doses and energies and the a-Si:H layer thickness are very different from literature experiments, since the latter targeted thin film a-Si:H solar cell applications.

Doping/passivation discussions: Because of a higher doping species activation efficiency and enhanced damages with higher ion implantation energies, we observe a trade-off between passivation and doping. At first sight the higher the energy, the higher the conductivity and the lower the passivation recovery.

The control of both the passivation and the conductivity by the ion implantation energy (Figures 1 and 2) is quite surprising compared to literature results, that rather report a control of doping by the ion dose. ${ }^{[7,19,20,22]}$ These differences might originate from the much higher a-Si:H layer thickness of literature studies $(\sim 100 \mathrm{~nm})$ and the very different implantation parameters. The observed evolution of our samples properties upon temperature annealing might be related to changes in the hydrogen configuration. However, no obvious change was observed in the absorption spectra from Fourier Transform InfraRed spectroscopy performed before and after annealing.

A complementary test with a prolonged $300^{\circ} \mathrm{C}$ annealing for $2 \mathrm{~h}$ $30 \mathrm{~min}$ has also been performed in order to further benefit from the $300^{\circ} \mathrm{C}$ annealing for both the doping and passivation properties. Such prolonged annealing succeeded in slightly increasing the conductivity and the lifetime of 1000 and 1500 V-implanted samples. The best results have been obtained for a trade-off with an $\mathrm{i}-V_{\mathrm{OC}}$ value of $710 \pm 5 \mathrm{mV}$ and an effective conductivity value of $3 \pm 1 \times 10^{-5} \Omega^{-1} \mathrm{~cm}^{-1}$ for the $1000 \mathrm{~V}-1 \times 10^{16} \mathrm{~cm}^{-2}$ sample.

$M P C$ measurements: Figure 3 introduces the $\mathrm{MPC}^{[16]}$ measurement results of the samples implanted at $500 \mathrm{~V}$ and 

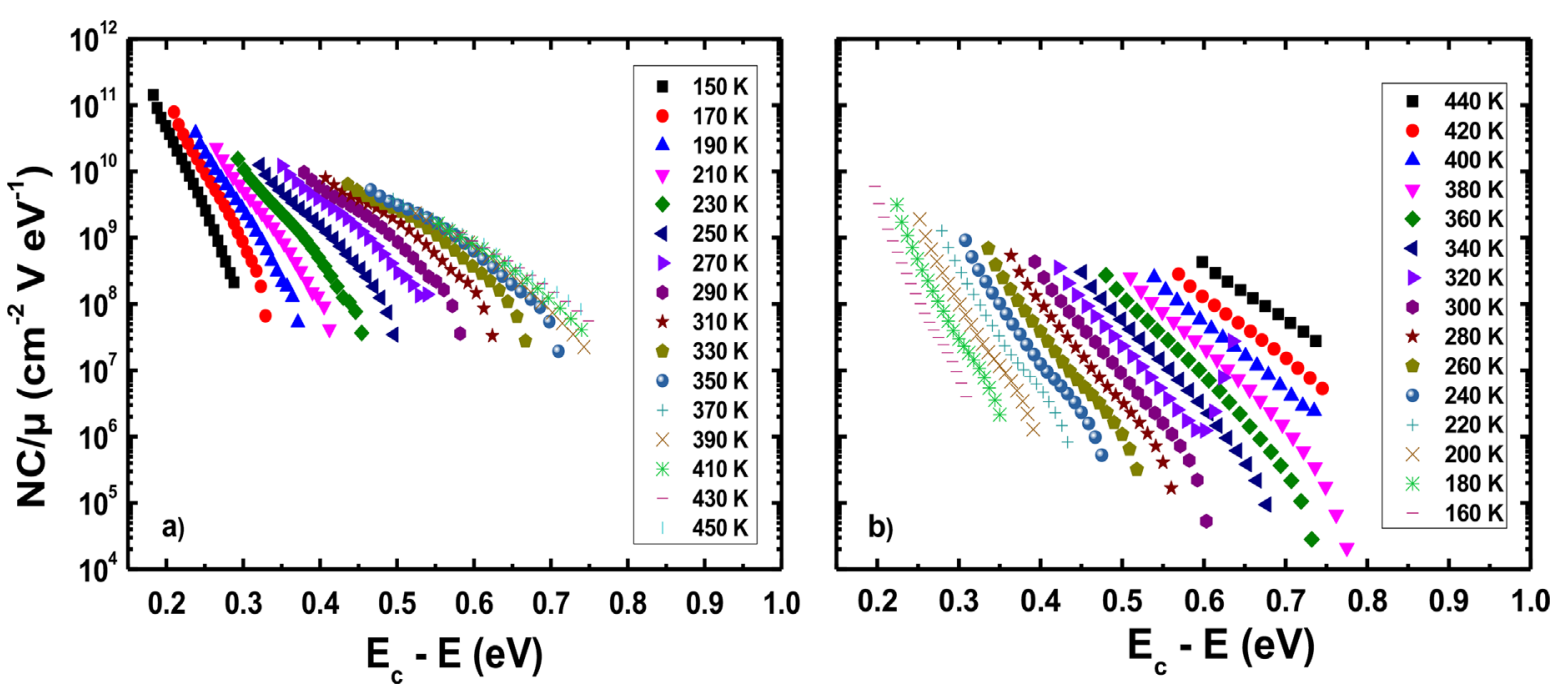

Figure 3. MPC measurement results of a-Si:H layer with a $\mathrm{B}_{2} \mathrm{H}_{6}-\mathrm{PIII}$ at $500 \mathrm{~V}$ and $10^{16} \mathrm{~cm}^{-2}$ (a) after PIII and (b) after PIII and annealing at $440 \mathrm{~K}$ for $60 \mathrm{~min}$.

$10^{16} \mathrm{~cm}^{-2}$ after the implantation step. The graph displays the $N C / \mu$ ratio calculated in the high frequency MPC regime assumption for various temperatures and 21 frequencies (ranging from $12 \mathrm{~Hz}$ to $39.9 \mathrm{kHz}$ in geometric progression), $N$ being the DOS, $C$ the capture coefficient, and $\mu$ the mobility of the carriers, that give the major contribution to the modulated photocurrent, as a function of the energy in the gap referred to the band edge. Due to the larger valence band tail compared to the conduction band tail, and to lower mobility of holes compared to that of electrons in a-Si:H, it is likely that the probed states in the high frequency regime of MPC are electron trapping states, thus explaining that the energy scale has been referred to the conduction band edge.

After PIII, the $N C / \mu$ values at different temperatures overlap at high frequency (i.e., lowest $E_{\mathrm{c}}-E$ values at each temperature). The overlapped regions forming the upper envelope can be considered as representative of the DOS shape in the material. The absolute value of $N C / \mu\left(10^{11} \mathrm{~cm}^{-2} \mathrm{VeV}^{-1}\right.$ at $\left.0.2 \mathrm{eV}\right)$ is much higher than for intrinsic samples reported in literature (by two orders of magnitude). ${ }^{[23,24]}$ This primarily indicates that PIII implantation in a-Si:H induces a high density of localized states that can prevent the Fermi level from moving close to the valence band, thus leading to a poor doping effect.

After annealing, a strong decrease of $N C / \mu$ value (about two orders of magnitudes) is observed, which indicates a significant decrease in the localized density of states upon annealing. The shape of the curves has also changed and the overlap of the curves at high frequency is mainly lost, which points toward strong changes in the microstructure of the material, like a possible partial crystallization and/or doping activation together with a reduction in defect density (C. Longeaud, private communication), although we could not find a proof of crystallization from spectroscopic ellipsometry and Raman measurements. ${ }^{[25]}$

This result is a direct observation of DOS evolution in ion implanted a-Si:H layers, and confirms indirect observations of DOS decrease upon annealing, characterized by photo-conductance.
It is also consistent with previous works in literature that indirectly observed that (i) ion implantation introduces a large amount of localized defects in a-Si:H, due to structural defects (dangling bonds, floating bonds, strained $\mathrm{Si}-\mathrm{Si}$ bonds, vacancy-like defects) ${ }^{[26]}$, and (ii) the increase in samples conductivity upon annealing originates from a defect recovery. ${ }^{[19,27]}$

Dark- and photo-conductivity: In order to further support the latter DOS behavior analysis, the $500 \mathrm{~V}$ and $10^{16} \mathrm{~cm}^{-2}$ implanted samples have been also characterized by means of dark- and photo-conductivity (DC and PC, respectively), as a function of temperature (Figure 4a). The temperature is first increased from 110 to $450 \mathrm{~K}$, a $450 \mathrm{~K}$ annealing is performed for $30 \mathrm{~min}$, and the temperature is then decreased from 450 to $110 \mathrm{~K}$. First it is observed that the DC has an activated behavior above $300 \mathrm{~K}$ and the corresponding activation energy decreases from 1.0 to $0.6 \mathrm{eV}$ after the $450 \mathrm{~K}$ annealing step, revealing a clear shift of the Fermi level. Moreover, the PC at and below room temperature is increased by more than two orders of magnitude after annealing. Since deep-localized states act as recombination centers for excess carriers, ${ }^{[27]}$ this behavior supports the DOS evolution observed from MPC in the previous section. One can also note a slight PC increase when sweeping from high to low temperature. Such behavior is probably related to the activation of localized defects with softer recombination parameters (i.e., lower capture cross sections).

The photosensitivity after each process step is presented in Figure $4 \mathrm{~b}$. It is decreased after the PIII step, validating the increase in the DOS after PIII. Stronger implantation energies lead to stronger damages (i.e., higher DOS), and thus, to a stronger photosensitivity decrease. After annealing at $150^{\circ} \mathrm{C}$, the photosensitivity increases because of the DOS decrease. Such DOS recovery is higher for the more lowly damaged samples (i.e., those implanted at lower energies). Finally, at higher annealing temperatures the photosensitivity decreases again, which may be related to the dopant activation, leading to an increase of the dark conductivity (see Figure 2). 

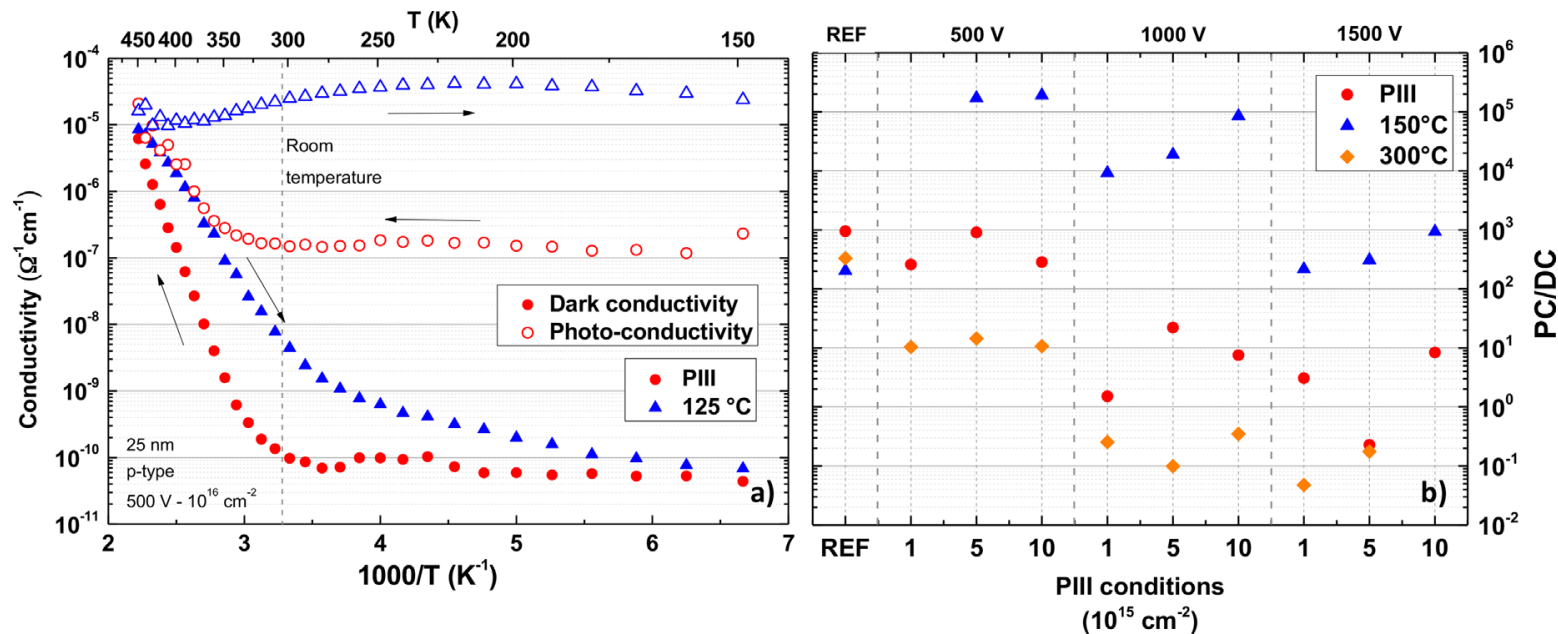

www.solar-rrl.com

4. (a) Dark- (DC) and photo (PC)-conductivity measurement after a $500 \mathrm{~V}$ and $10^{16} \mathrm{~cm}^{-2} \mathrm{PIII} \mathrm{B}_{2} \mathrm{H}_{6}$ implantation against temperature. (b) Room temperature photosensitivity after each process step and against different PIII implantation conditions. For this latter experiment only, a $630 \mathrm{~nm}$ illumination at a flux of $2.6 \times 10^{16} \mathrm{~cm}^{-2} \mathrm{~s}^{-1}$ is used.

As a result, the analysis of the photo-conductivity and photosensitivity behavior are well correlated to the MPC results and suggest changes in the DOS after PIII and subsequent annealing steps.

Conclusion: In this work, the doping/passivation trade-off of boron-implanted thin a-Si:H layers has been investigated.

After plasma immersion ion implantation, conductivities of a-Si:H layers and effective lifetimes of a-Si:H/c-Si/a-Si:H samples are very low, due to a poor doping activation and strong a-Si:H/c-Si interface damages. A post-implantation hot plate annealing is successfully used to recover (at least partially) both properties. After annealing samples implanted at higher energies exhibit higher conductivities. The conductivity increase is directly (from MPC) and indirectly (from dark- and photoconductivity) observed to originate from a strong decrease of the density of states in a-Si:H. Field-effect passivation is also evidenced for layers exhibiting a high conductivity.

Promising results have been achieved using PIII acceleration voltage of $1000 \mathrm{~V}$ and implanted dose of $1 \times 10^{16} \mathrm{~cm}^{-2}$, with a-Si: $\mathrm{H}$ layers exhibiting reasonable room temperature conductivity, $\sigma_{\mathrm{RT}}=3 \pm 1 \times 10^{-5} \Omega^{-1} \mathrm{~cm}^{-1}$, and leading to high implied open circuit voltage, $\mathrm{i}-V_{\mathrm{OC}}=710 \pm 5 \mathrm{mV}$, after prolonged annealing at the highest tested annealing temperature $\left(150 \mathrm{~min}\right.$ at $\left.300^{\circ} \mathrm{C}\right)$.

The monotonous increase of passivation and doping properties with annealing temperature suggests that higher temperature should provide improved layer properties. Therefore, together with a finer implantation parameters tuning, there is space for promising improvements. The doping of (p) a-Si:H layers now appears as a very promising way of processing IBCSHJ solar cells.

\section{Acknowledgements}

The authors would like to acknowledge F. Milesi and P. Mur from CEA Léti for all the ion implantation processes. They also thank the French Environment and Energy Management Agency (ADEME) and the French Alternative Energies and Atomic Energy Commission (CEA) for funding this work. This study was also supported by the European Union through the HERCULES project that has received funding from the European Union's Seventh Programme for research, technological development, and demonstration under grant agreement no. 608498 .

Received: November 5, 2016 Revised: December 18, 2016 Published online: February 7, 2017

[1] Adachi, D., Hernández, J. L., Yamamoto, K., Appl. Phys. Lett. 2015, 107, 233506.

[2] Green, M. A., Emery, K., Hishikawa, Y., Warta, W., Dunlop, E. D, Prog. Photovoltaics Res. Appl. 2016, 24, 905.

[3] Masuko, K., Shigematsu, M., Hashiguchi, T., Fujishima, D., Kai, M., Yoshimura, N., Yamaguchi, T., Ichihashi, Y., Mishima, T., Matsubara, N., Yamanishi, T., Takahama, T., Taguchi, M., Maruyama, E., Okamoto, S., IEEE J. Photovolt. 2014, 4, 1433.

[4] Desrues, T., De Vecchi, S., d'Alonzo, G., Munoz, D., Ribeyron, P.-J., Influence of the emitter coverage on interdigitated back contact (IBC) silicon heterojunction (SHJ) solar cells, in IEEE 40th Photovoltaic Specialists Conference, Denver, 2014, p. 857.

[5] Paviet-Salomon, B., Tomasi, A., Descoeudres, A., Barraud, L., Nicolay, S., Despeisse, M., De Wolf, S., Ballif, C., IEEE J. Photovolt. 2015, 5, 1293.

[6] Nakamura, C., Asano, N., Hieda, T., Okamoto, C., Katayama, H., Nakamura, K., IEEE J. Photovolt. 2015, 4, 1491.

[7] Müller, G., Kalbitzer, S., Spear, W. E., Le Comber, P. G., Doping of amorphous silicon by ion implantation, in 7 th International Conference on Amorphous and Liquid Semiconductors 1977, edited by W. E. Spear (CICL, University of Edinburgh), p. 442.

[8] Spear, W. E., Le Comber, P. G., Kalbitzer, S., Mueller, G., Philos. Mag. B 1979, 39, 159.

[9] Kalbitzer, S., Mueller, G., Le Comber, P. G., Spear, W. E., Philos. Mag. B 1980, 41, 439.

[10] Defresne, A., Plantevin, O., Sobkowicz, I. P., Bourçois, J., Roca. i Cabarrocas, P., Nucl. Instr. Meth. B 2015, 365, 133.

[11] Torregrosa, F., Laviron, C., Faik, H., Barakel, D., Milesi, F., Beccaccia, S., Surf. Coat. Technol. 2004, 186, 93.

[12] Etienne, H., Vervisch, V., Torregrosa, F., Sarnet, T., Delaporte, P., Cristiano, F., Fazzini, P. F., Roux, L., Sempere, G., Ultra shallow 
junctions fabrication by Plasma Immersion Implantation on PULSION $^{\text {in }}$ followed by different annealing processes, in Extended Abstracts - 2008 8th International Workshop on Junction Technology (IWJT' '08) 2008, p. 32.

[13] Felch, S. B., Fang, Z., Koo, B.-W., Liebert, R. B., Walther, S. R., Hacker, D., Surf. Coat. Technol. 2002, 156, 229.

[14] Jellison, J. G. E., Modine, F. A., Appl. Phys. Lett. 1996, 69, 371.

[15] Sinton, R. A., Cuevas, A., Stuckings, M., Quasi-steady-state photoconductance, a new method for solar cell material and device characterization, in 25th IEEE Photovoltaic Specialists Conference, Washington DC, 1996, p. 457.

[16] Kleider, J.-P., Longeaud, C. Gueunier, M.-E., Phys. Status Solidi (C) 2004, 1, 1208.

[17] Illiberi, A., Kudlacek, P., Smets, A. H. M., Creatore, M., van de Sanden, M. C. M., Appl. Phys. Lett. 2011, 98, 242115.

[18] De Wolf, S., Kondo, M., Appl. Phys. Lett. 2007, 91, 112109.
[19] Müller, G., Le Comber, P. G., Philos. Mag. B 1981, 43, 419.

[20] Le Comber, P. G., Spear, W. E., Müller, G., Kalbitzer, S., J. Non Cryst. Solids 1980, 35, 327.

[21] Zhang, D., Deligiannis, D., Papakonstantinou, G., van Swaaij, R. A., Zeman, M., IEEE J. Photovolt. 2014, 4, 1326.

[22] Van Der Weg, W. F., Berntsen, A. J. M., Saris, F. W., Polman, A., Mater. Chem. Phys. 1996, 46, 140.

[23] Luckas, J., Longeaud, C., Siebentritt, S., J. Appl. Phys. 2014, 116, 103710.

[24] Longeaud, C., Schmidt, J., Koropecki, R. R., Kleider, J.-P., J. Optoelectron. Adv. Mater. 2009, 11, 1064.

[25] Shahidul Haque, M., Naseem, H. A., Brown, W. D., J. Appl. Phys. 1994, 75, 3928.

[26] Coffa, S., Priolo, F., Battaglia, A., Phys. Rev. Lett. 1993, 70, 3756.

[27] Galloni, R., Tsuo, Y. S., Baker, D. W., Zignani, F., Appl. Phys. Lett. 1990, 56, 241. 